\title{
The Solidification Metallurgy of Alloy 718 and Other $\mathrm{Nb}$-Containing Superalloys*
}

\author{
M. J. Cieslak, G. A. Knorovsky, T. J. Headley, A. D. Romig, Jr. \\ Sandia National Laboratories \\ Albuquerque, New Mexico 87185
}

\begin{abstract}
The solidification behavior of Alloy 718 and other $\mathrm{Nb}$-bearing austenitic superalloys has been examined using an integrated analytical approach. All alloys of this type begin solidification with the formation of $\mathrm{Nb}$-lean austenitic dendrites. Interdendritic eutectic-type solidification constituents invovling MC-type carbides and a Nb-rich Laves phase occur in these alloys. The $\gamma /$ Laves euetctic constituent terminates solidification in these alloys. $\mathrm{Nb}$ is the dominant element in the evolution of solidification microstructure with $\mathrm{C}$ and $\mathrm{Si}$ affecting the amounts of $\gamma / \mathrm{MC}$ and $\gamma /$ Laves constituent observed. Simple solidification models predict reasonably well the amount of eutectic constituent observed.
\end{abstract}

*This work performed at Sandia National Laboratories supported by the U.S. Dept. of Energy under contract number DE-AC04-76DP00789.

\footnotetext{
Superalloy 718-Metallurgy and Applications

Edited by E A Loria

The Minerals, Metals \& Materials Society, 1989
} 


\section{Introduction}

The technological importance of Alloy 718 is best understood by recognizing the various product forms in which it appears. In particular, Alloy 718 is often found in engineering applications requiring the use of solidification processing (e.g. welding, casting). Indeed, it was the need for a "weldable" superalloy that, in part, led to the development of Alloy 718[1]. The present paper describes the solidification behavior of Alloy 718, predominantly at cooling rates approximating those of conventional arc welding and casting. For comparison purposes, the solidification behavior of other $\mathrm{Nb}$-containing $\mathrm{Ni}$ and $\mathrm{Ni}-\mathrm{Fe}$ alloys such as Alloy 625 and Incoloy 909 are examined and discussed. Fundamental solidification quantities (liquidus, solidus, and terminal eutectic-like reaction temperatures) and a description of the development of the solidification microstructure will be presented. A pseudo-binary-like, $\gamma$-matrix/ $\mathrm{Nb}$ solidification constitution diagram for Alloy 718 is developed.

\section{Experimental}

Techniques used to examine the alloys discussed in the series of investigations[2-4] collected here include differential thermal analysis (DTA), gas-tungsten-arc (GTA) and plasma arc welding, and optical and electron microscopy (scanning and analytical electron microscopy (AEM), electron probe microanalysis). The various alloys (Alloy 718, Alloy 625, Incoloy ${ }^{B}$ 909) examined have the compositions listed in Table I.

Differential thermal analysis experiments were performed on a Netsch Thermal Analyzer STA 429. Heating and cooling rates of $0.33^{\circ} \mathrm{C} / \mathrm{s}$ were employed. Samples weighed $\approx 0.8$ grams. The crucible material was high purity alumina. All tests were run in an inert gas (either Ar or $\mathrm{He}$ ) environment. Nickel and tungsten were used for the standards. Reaction temperatures were defined as deviations from the local baseline.

Many of the detailed analyses of solidification microstructure were performed on arc welds made on these alloys. Weldability considerations were the driving force for the studies performed. The details of the weldability experiments and welding conditions are given in the references [2-4].

Analysis of the solidification microstructures in both DTA and welding specimens began with optical and scanning electron microscopy. Samples were polished through $0.05 \mu \mathrm{m}$ alumina and then electroetched in a chromic acid solution for times necessary to reveal the

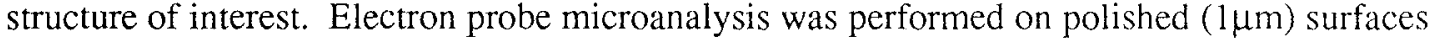
with a Cameca MBX electron microprobe. Analyses were typically performed in the spot mode $(\approx 1 \mu \mathrm{m} \mathrm{x}$-ray spatial resolution) at $20 \mathrm{kV}$ with a beam current of $20 \mathrm{nA}$. Analytical electron microscopy was performed using either a JEOL-100C AEM operated at $100 \mathrm{kV}$ or a JEOL $2000 \mathrm{FX}$ AEM operated at $200 \mathrm{kV}$. Selected-area electron diffraction (SAD) was used to identify the phases of interest. Microchemical information for minor phase compositions was obtained with energy dispersive spectrometry (EDS). The reduction of EDS data to weight percentages and the detailed description of the microanalytical techniques employed are reported elsewhere[2].

\section{$\underline{\text { Results }}$}

Representative DTA thermograms for Alloy 718, Incoloy 909, and Alloy 625 are shown in Figs. 1-3. Fig. 1 shows the reactions involved in the melting and solidification of Alloy 718 . The on-heating portion of this figure shows an event occurring at $\approx 1230^{\circ} \mathrm{C}$, which represents the dissolution/liquation of MC (predominantly NbC) carbide. The inflection point at $\approx 1297^{\circ} \mathrm{C}$ represents the matrix $(\gamma)$ solidus. The peak of the DTA thermogram, $\approx 1351^{\circ} \mathrm{C}$, is the alloy 
liquidus[5]. The on-cooling portion of the figure shows that supercooling of the melt in the alumina crucible has driven the liquidus temperature down to $\approx 1328^{\circ} \mathrm{C}$. The break point at $\approx$ $1257^{\circ} \mathrm{C}$ represents the solidification of the $\gamma / \mathrm{MC}(\mathrm{NbC})$ constituent. Solidification does not end at this point but continues until $\approx 1185^{\circ} \mathrm{C}$ where the $\gamma /$ Laves eutectic reaction terminates solidification.

Figure 2 shows the reactions involved in the melting and solidification of Incoloy 909. This $\mathrm{Fe} / \mathrm{Ni}$ alloy contains very little carbon $(0.003$ wt. $\%$ ) and shows no evidence of a dissolution/liquation event prior to the matrix solidus $\left(\approx 1263^{\circ} \mathrm{C}\right)$. The liquidus occurs at $\approx$ $1400^{\circ} \mathrm{C}$. On cooling, nucleation of solid occurs at $\approx 1384^{\circ} \mathrm{C}$. Solidification terminates at $\approx$ $1198^{\circ} \mathrm{C}$ with the formation of a $\gamma /$ Laves constituent.

Figure 3 shows the reaction involved in the melting and solidification of Alloy 625. This alloy contains more $\mathrm{Ni}(\approx 62 \mathrm{wt} . \%)$ and less $\mathrm{Nb}(\approx 3.5 \mathrm{wt} \%)$ than do either Alloy 718 or Incoloy 909. The first reaction on heating is the dissolution/liquation of $\mathrm{MC}(\mathrm{NbC})$ carbide at $\approx$ $1255^{\circ} \mathrm{C}$. The alloy solidus is reached at $\approx 1283^{\circ} \mathrm{C}$ and the liquidus occurs at $\approx 1363^{\circ} \mathrm{C}$. On cooling, the liquidus occurs at $\approx 1333^{\circ} \mathrm{C}\left(30^{\circ} \mathrm{C}\right.$ undercooling $) . \mathrm{Al} \approx 1231^{\circ} \mathrm{C}$, the $\gamma / \mathrm{MC}(\mathrm{NbC})$ reaction occurs. Solidification terminates at $\approx 1158^{\circ} \mathrm{C}$ with the formation of the $\gamma /$ Laves constituent.

The microstructure of the Alloy 718 GTA welding and DTA specimens consisted of primary matrix $(\gamma)$ dendrites and interdendritic eutectic-type constituents involving Laves phase and $\mathrm{MC}(\mathrm{NbC})$ carbides. Figure $4(\mathrm{a}, \mathrm{b})$ shows examples of these two constituents, from GTA weld metal, identified by selected area electron diffraction. Of the two constituents, the $\gamma /$ Laves was by far the more predominant in terms of volume fraction. The interlamellar $\gamma$ associated with the $\gamma /$ Laves constituent contained very fine $\gamma^{\prime \prime}$ precipitates (Fig. 5) which formed during cooling of the weld metal. Incoloy 909 contained only a single minor interdendritic constituent which was identified by SAD as Laves phase. Figure 6 shows an example of this constituent in weld metal and reveals a characteristic heavily faulted appearance. The interdendritic constituents in Inconel 625 were identified by SAD as involving both $\mathrm{MC}(\mathrm{NbC})$ carbide and Laves phase. Figure 7 is a TEM micrograph which shows the minor phases observed in this weld metal microstructure.

The segregation of alloying elements during dendritic solidification (DTA sample) of Alloy 718 is shown in Fig. 8. The dendrite core regions (DC) are are depleted in $\mathrm{Nb}, \mathrm{Si}$, Ti, and Mo relative to the bulk composition whereas $\mathrm{Fe}$ and $\mathrm{Cr}$ are enriched relative to the bulk composition. Ni and Al show very little intradendritic segregation. The interdendritic phases are all $\mathrm{Nb}$ rich.

The compositions of the various phases found in the solidification structures were determined by the reduction of AEM/EDS data obtained on either thin foils or extraction replicas. Table II lists these phase compositions obtained from weld metal samples. Other critical compositions (from microprobe) are also given.

\section{Discussion}

The solidification behaviors of these alloys are characterized by terminal solidification events involving $\mathrm{Nb}$-bearing phases (Laves and $\mathrm{MC}(\mathrm{NbC})$ ). In Alloy $718, \gamma /$ Laves is the predominant minor constituent observed. The reaction path leading to the development of the observed solidification microstructure may be best understood by examining the microprobe profiles in Fig. 8 and the composition data in Table II. In particular, the distribution of Nb shows that the dendrite core (DC) regions are depleted relative to the nominal concentration, implying an effective solidification distribution coefficient, $k$, less than unity. Table II reveals that the dendrite core $\mathrm{Nb}$ concentration is $2.5 \mathrm{wt} . \%$. With a nominal concentration of $5.25 \mathrm{wt}$.\%, a value of $\mathrm{k}$ of $\approx 0.5(2.5 \mathrm{wt} . \% / 5.25 \mathrm{wt} . \%)$ results. Another measure of $\mathrm{k}$ can be obtained by taking the ratio of $\mathrm{Nb}$ concentration at the maximum solid solubility (Interlamellar $\gamma$, Table II) to that in the eutectic $\gamma /$ Laves constituent (Table II) from the weld metal samples. This calculation 
also results in a value of $\approx 0.5(9.6 \mathrm{wt} . \% / 19.1 \mathrm{wt} . \%)$. Using a simple Scheill6] solidification model and ignoring the presence of the $\gamma / \mathrm{MC}(\mathrm{NbC})$ constituent, a volume fraction of the $\gamma /$ Laves eutectic constituent equal to $\approx 7.5 \%$ is predicted. Image analysis of the 718 DTA sample revealed an average volume fraction of $5.4 \%(0.9 \%$ standard deviation) euetctic constituent. Effects of solid state diffusion during solidification and dissolution of the metastable Laves during cooling from the solidus (both of which reduce the volume fraction of Laves) were not taken into account in this calculation.

Similar solidification behavior occurs for Incoloy 909 and Alloy 625. The distribution coefficient for $\mathrm{Nb}$ in both alloys is $\approx 0.5$, implying segregation of $\mathrm{Nb}$ to terminal solidification (interdendritic) volumes in a manner analogous to Alloy 718. In the case of Incoloy 909 the carbon content is sufficiently low to preclude the formation of a $\gamma / \mathrm{MC}(\mathrm{NbC})$ constituent. The relatively high Si and $\mathrm{C}$ contents of the Alloy 625 examined are such that both $\gamma /$ Laves and $\gamma / \mathrm{MC}(\mathrm{NbC})$ constituents form. The lower $\mathrm{Nb}$ concentration of Alloy 625 results in a much lower volume fraction of eutectic constituents (image analysis revealed a total minor constituent population of $\approx 1 \%$ ) in comparison to either Alloy 718 or Incoloy 909 (6.3\% from image analysis).

From the data in Table II elements which likely promote the formation of the $\gamma /$ Laves eutectic constituent (compare Laves with Interlamellar $\gamma$ ) are $\mathrm{Si}, \mathrm{Nb}$, and Mo. The extensive partitioning behavior of Si suggests that it strongly promotes the formation of the $\gamma /$ Laves eutectic[2]. The stabilizing influence of Si on Laves formed in the solid state was observed almost 3 decades ago by Wlodek[7]. It is also interesting to note that while no $\mathrm{Ni}_{2} \mathrm{Nb}$ Laves phase is known to exist, a ternary Laves phase of the form $\mathrm{Ni}_{3} \mathrm{SiNb}_{2}$ has been observed by Bardos et al.[8]. Si has also been shown[9] to promote a $\gamma /$ Laves eutectic constituent in IN-519 (Fe-24Cr-24Ni-1.5 Nb wt.\%). The behavior of Ti deserves discussion. As seen in Table II, within the $\gamma /$ Laves eutectic constituent in both Alloy 718 and Incoloy 909, the Ti partitions preferentially to the $\gamma$ phase. This same partitioning behavior was also recently confirmed in a weldability study of Carpenter Custom Age 625 PLUS $^{\circledR}[10]$. As Ti forms the prototypic hexagonal Laves phase with $\mathrm{Fe}[11]$, this behavior would not be easily predictable. The implication of these observations is that in $\mathrm{Nb}$-bearing superalloys, the role of $\mathrm{Ti}$ in the evolution of solidification microstructure is clearly subordinate to elements such as $\mathrm{Nb}, \mathrm{C}$, and $\mathrm{Si}$.

Finally, using the collected analytical (D'A and phase composition) data, a solidification constitution diagram (ignoring interstitials) for Alloy 718[3], similar to the one proposed by Eiselstein[1] , can be constructed which serves a useful tutorial purpose. Figure 9 shows this diagram. Points 1 and 2 are the liquidus and solidus, respectively, of the bulk alloy. Point 3 is the dendrite core composition (first solid to form at liquidus temperature). Points 4-6 are the tie-line points of the $\gamma /$ Laves eutectic reaction. Point 7 is from Eiselstein[1]. This diagram is drawn as a $\gamma$-matrix/ $\mathrm{Nb}$ pseudo-binary because $\mathrm{Nb}$ is the element which exerts primary control over the solidification microstructure development in Alloy 718. The eutectic-like form of this diagram is consistent with the observed microstructure.

\section{Conclusion}

The solidification metallurgy of Alloy 718 (and other Nb-bearing superalloys) is dominated by the segregation behavior of $\mathrm{Nb}$ and the formation of $\mathrm{Nb}$-rich, eutectic-like constituents of the form $\gamma /$ Laves and $\gamma / \mathrm{MC}(\mathrm{NbC})$. Si and $\mathrm{C}$ also influence the minor constituent population. Simple models can be used to describe the microstructural evolution during solidification with good accuracy. A pseudo-binary constitution diagram has been developed which provides a good visual tool for understanding the solidification behavior of Alloy 718 .

\section{Acknowledgement}

The authors wish to thank T. Lienert, M. McAllaster, R. E. Semarge, T. Kollie, W. Sorenson, and W. Swartout for their assiatnce. This work was performed at Sandia National Laboratories supported by the U.S. Dept. of Energy under contract number DE-AC04-76DP00789. 


\section{References}

1. H. L. Eiselstein, Advances in the Technology of Stainless Steels, "Metallurgy of a Columbium-Hardened Nickel-Chromium-Iron Alloy", ASTM STP 369, 1965, pp. 62-79.

2. M. J. Cieslak, T, J. Headley, T. Kollie, and A. D. Romig, Jr., "A Melting and Solidification Study of Alloy 625", Metallurgical Transactions $\Lambda, 19 \Lambda(9)(1988)$, pp. 2319-2331.

3. G. A. Knorovsky, M. J. Cieslak, T. J. Headley, A. D. Romig, Jr., and W. F. Hammetter, "Inconel 718: A Solidification Diagram", accepted for publication in Metallurgical Transactions A.

4. M. J. Cieslak, T. J. Headley, G. A. Knorovsky, A. D. Romig, Jr., T. Kollie, "A Comparison of the Solidification Behavior of Incoloy 909 and Inconel 718", submitted to Metallurgical Transactions A, 11 January, 1988.

5. D. G. MacIssac, Y. Shiohara, M. G. Chu, and M. C. Flemings, Grain Refinement in Castings and Welds, AIME publication, G. J. Abbaschian and S. A. David, ed., 1983, pp. 87-96.

6. E. Scheil, Z. Metallk., 34(1942): 70.

7. S. T. Wlodek, Trans. Am. Soc. Met., 56 (1963) 287-303.

8. D. I. Bardos, K. P. Gupla, and P. A. Beck, Trans. TMS-AIME, 221 (1961) 1087.

9. Y. Nakao, H. Oshige, S. Koga, H. Nishihara, J. Sugitani, "Effect of Nb/C on the Sensitivity of Liquation Cracking in $24 \mathrm{Cr}-24 \mathrm{Ni}-1.5 \mathrm{Nb}$ Fe-base Heat Resisting Alloy" Journal of Japan Welding Society, 51(12)(1982), pp. 989-995.

10. M. J. Cieslak, T. J. Headley, R. B. Frank, "The Welding Metallurgy of Carpenter Custom Age 625 PLUS $®$ Alloy", paper submitted to the Welding Journal, January 1989.

11. T. Lyman et al., eds. Metals Handbook., vol. 8 (Metals Park, OH: ASM International, 1973), 307.

Note: Incoloy ${ }^{(1)}$ is a registered trademark of Huntington Alloys, Inc. Custom Age 625 PLUS ${ }^{\circledR}$ is a registered trademark of Carpenter Technology, Inc. 


\section{TABLE I.}

\section{Alloy Compositions (wt.\%)}

$\begin{array}{cccc}\text { Element } & \text { Incoloy } 909 & \text { Alloy } 718 & \text { Alloy } 625 \\ \mathrm{Fe} & 40.89 & 18.10 & 2.29 \\ \mathrm{Ni} & 38.83 & 53.20 & 62.27 \\ \mathrm{Cr} & - & 18.18 & 21.68 \\ \mathrm{Co} & 12.61 & 0.11 & - \\ \mathrm{Nb} & 5.13 & 5.25 & 3.53 \\ \mathrm{Mo} & - & 3.12 & 9.67 \\ \mathrm{Ti} & 1.50 & 0.95 & 0.06 \\ \mathrm{Al} & 0.02 & 0.56 & - \\ \mathrm{Si} & 0.48 & 0.21 & 0.46 \\ \mathrm{C} & 0.003 & 0.04 & 0.035 \\ \mathrm{~S} & 0.003 & 0.002 & 0.003\end{array}$

\section{TABLE II.}

Phase Composition Data (wt.\%) $)^{\S}$

\begin{tabular}{|c|c|c|c|c|c|c|c|}
\hline Phase & $\mathrm{Fe}$ & $\mathrm{Ni}$ & $\mathrm{Cr}$ & Co & $\mathrm{Nb}$ & Mo & Ti \\
\hline $\begin{array}{l}\text { Eutectic Laves* } \\
\text { (718) }\end{array}$ & 11.6 & 45.8 & 13.3 & & 22.3 & 4.6 & 1.2 \\
\hline Interlamellar $\gamma^{*}$ & 12.8 & 58.4 & 14.4 & & 9.6 & 2.8 & 1.6 \\
\hline $\begin{array}{l}\gamma / \text { Laves Eutectic }{ }^{\dagger} \\
(718)\end{array}$ & 11.4 & 48.6 & 13.2 & & 19.1 & 4.4 & 2.0 \\
\hline $\begin{array}{l}\text { Dendrite Core }{ }^{\dagger} \\
(718)\end{array}$ & 19.2 & 55.6 & 18.6 & & 2.5 & 2.7 & 0.6 \\
\hline $\begin{array}{l}\text { MC Carbide } \text { Ca* }^{*} \\
(718)\end{array}$ & 1.5 & 4.7 & 2.5 & & 80.4 & 2.5 & 8.4 \\
\hline $\begin{array}{l}\text { Eutectic Laves* } \\
(909)\end{array}$ & 22.4 & 31.3 & & 11.1 & 32.3 & & 2.1 \\
\hline $\begin{array}{l}\text { Interlamellar } \gamma^{*} \\
\text { (909) }\end{array}$ & 30.6 & 45.9 & & 11.0 & 9.4 & & 2.9 \\
\hline $\begin{array}{l}\text { Eutectic Laves* } \\
\text { (625) }\end{array}$ & 0.9 & 46.7 & 13.6 & & 16.8 & 19.8 & \\
\hline $\begin{array}{l}\text { MC Carbide } \\
(625)\end{array}$ & 0.5 & 5.1 & 5.8 & & 68.5 & 20.1 & \\
\hline
\end{tabular}



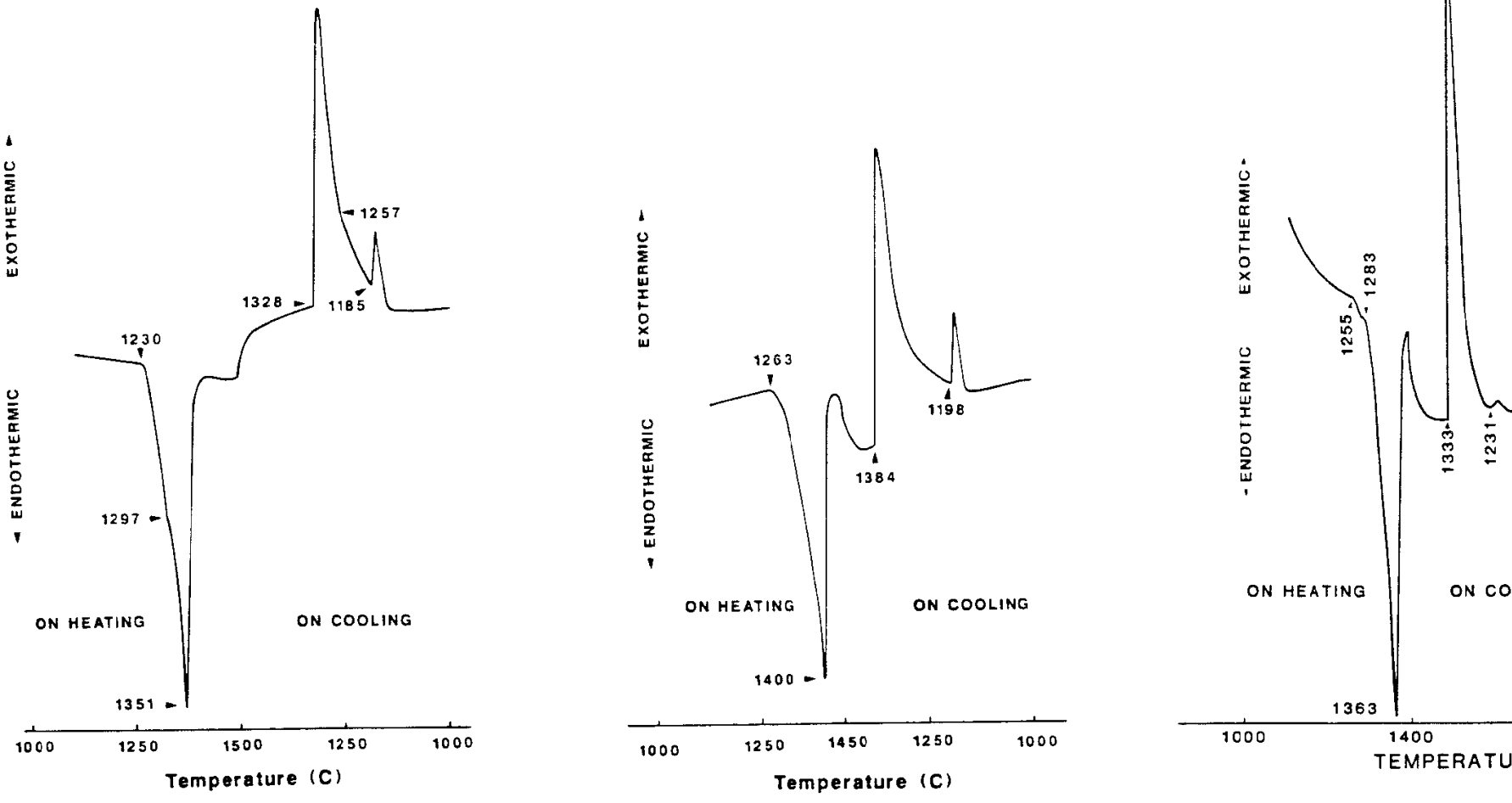

Fig. 1. DTA thermogram from Alloy 718. Fig. 2. DTA thermogram from Incoloy 909

Fig. 3. DTA thermogram $\mathrm{f}$ 

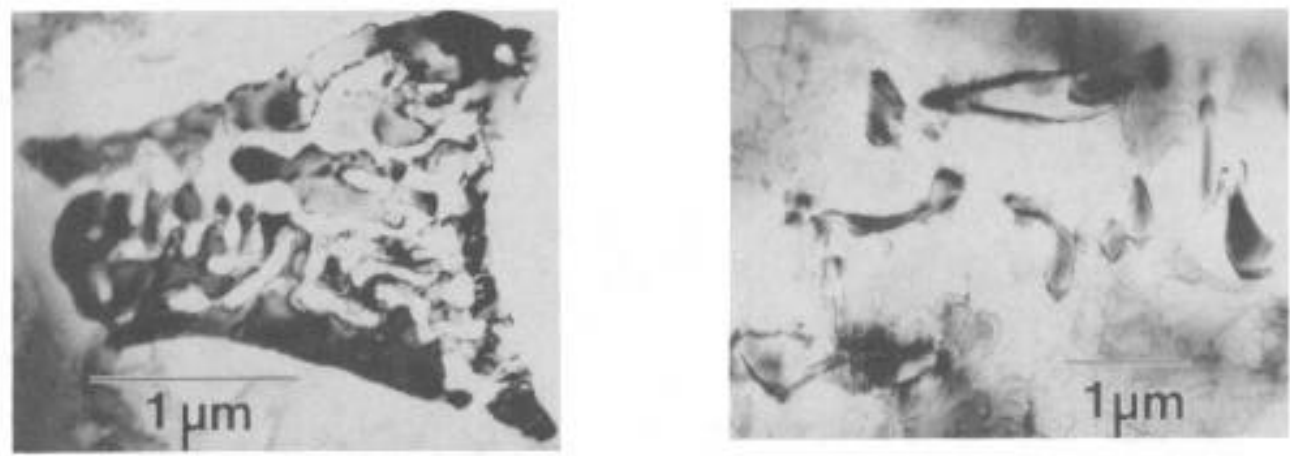

Fig. 4. TEM micrograph showing solidification constituents in Alloy 718 invovling (a) Laves phase, and (b) $\mathrm{MC}(\mathrm{NbC})$ carbide.

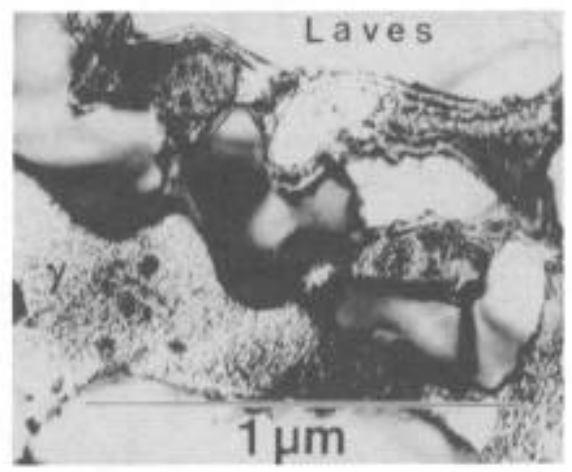

Fig. 5. TEM micrograph showing appearance of $\gamma^{\prime \prime}$ (speckled features) in eutectic $\gamma$ of Alloy 718.
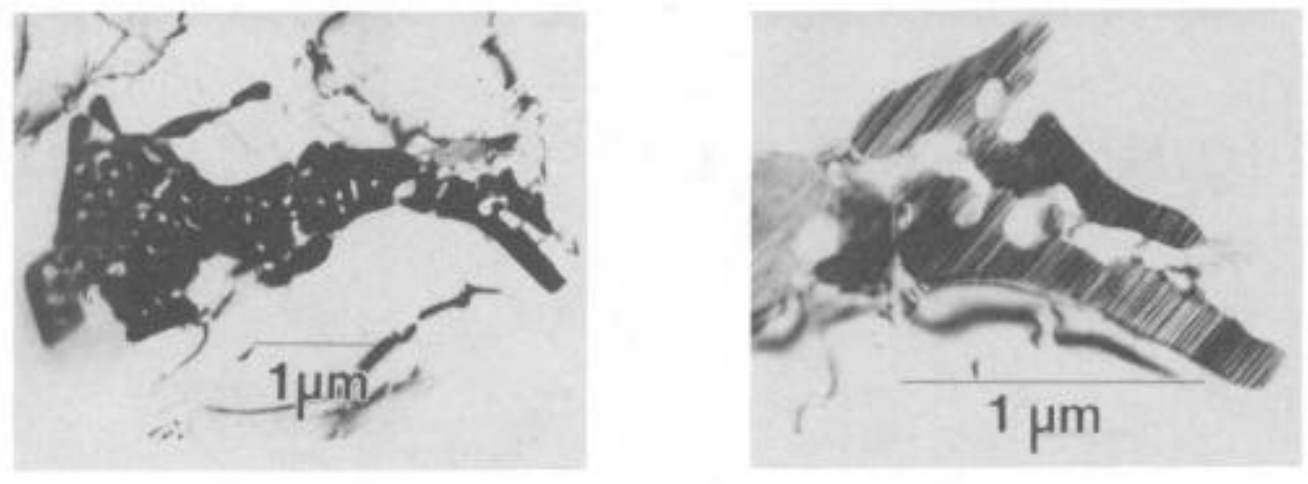

Fig. 6. (a) TEM micrograph showing solidification constituent in Incoloy 909 involving Laves phase; (b) higher magnification showing faulted structure of Laves.

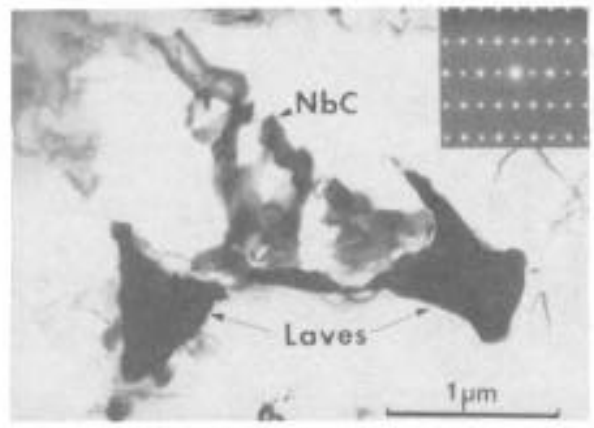

Fig. 7. TEM micrograph showing solidification constituents in Alloy 625. Diffraction pattern is the 1120 zone in Laves. 

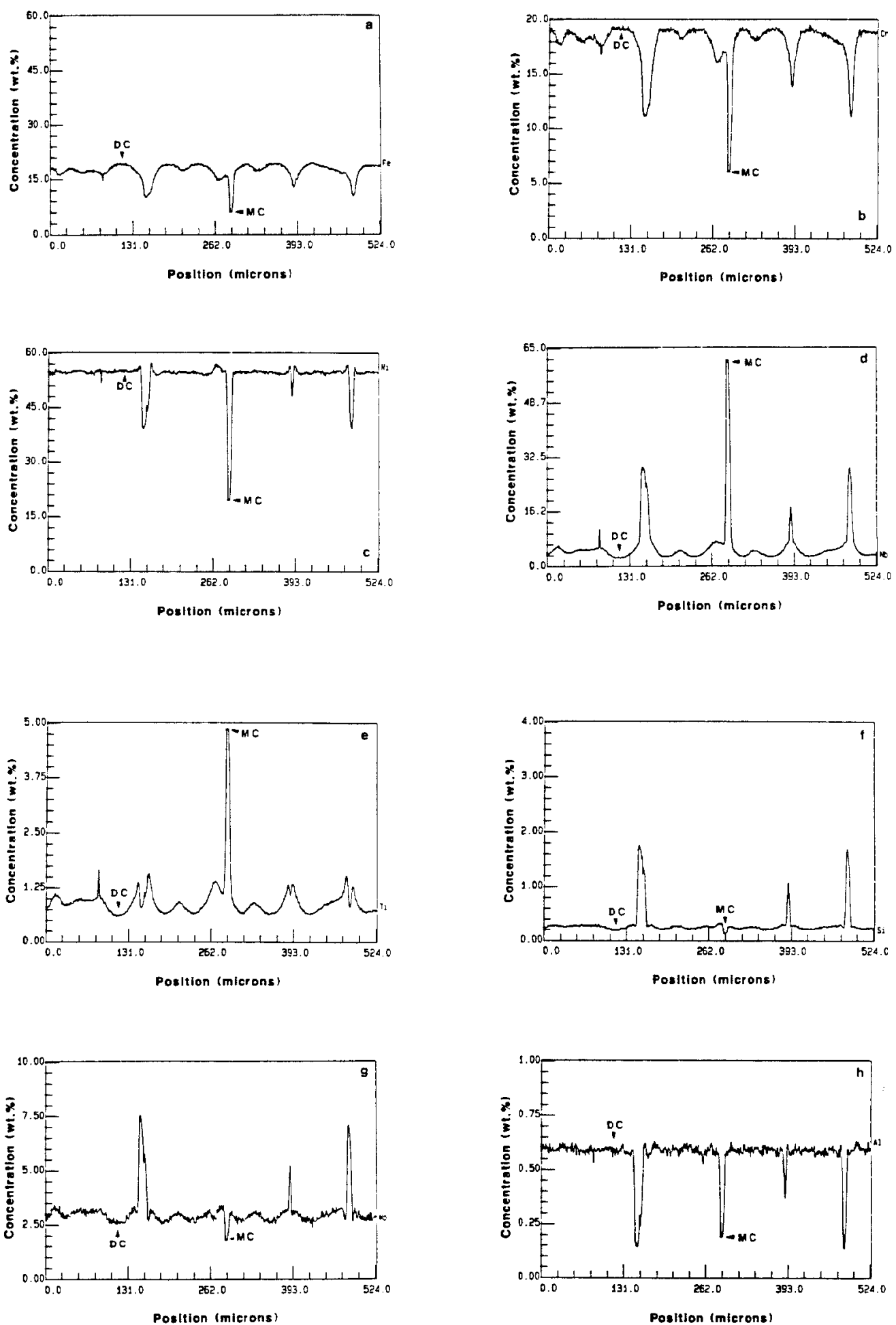

Fig. 8. Microprobe profiles obtained in Alloy 718 DTA specimen: (a) Fe, (b) $\mathrm{Cr}$, (c) Ni, (d) $\mathrm{Nb}$, (c) Ti, (g) Mo, (h) Al. DC indicates a dendrite core position. MC indicates a position where an $\mathrm{MC}(\mathrm{NbC})$ carbide is crossed. Note low $\mathrm{Si}$ at this point. 


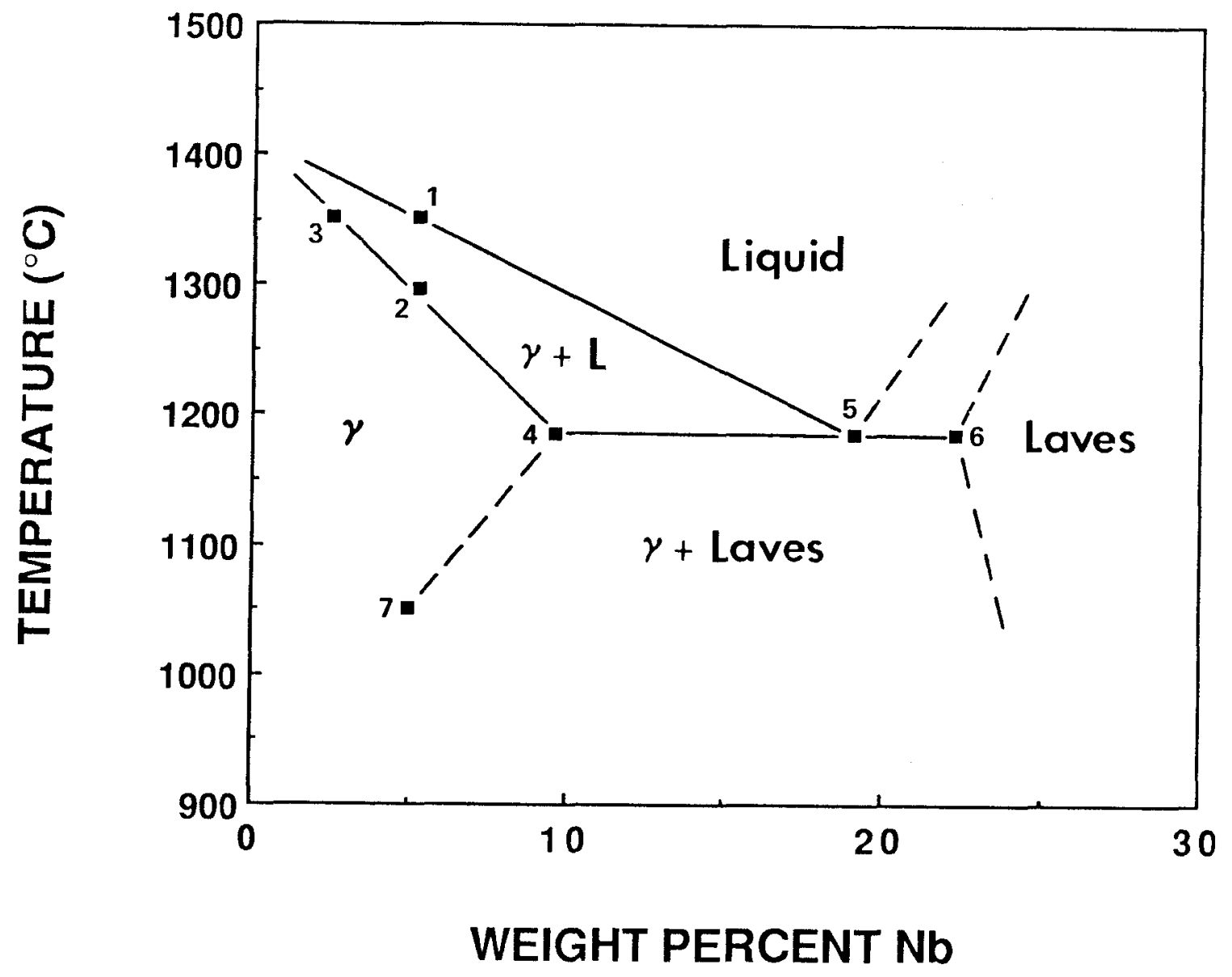

Figure 9. $\gamma$-matrix/Nb, pseudo-binary solidification constitution diagram for Alloy 718 . 